\title{
PENGEMBANGAN SISTEM MONITORING PENGELOLAAN ANGGARAN INVESTASI
}

Putri Nur Rositawati

Universitas Airlangga

\begin{abstract}
This study describes the management of investment budgets in PT. Pembangkitan Jawa Bali. The investment budget that has been running has not reached the target. During its development, it was found that there was a difference between revenue in the contract with planning budget and realization. The root cause problem-solving method was chosen to determine the root of the problem and solution. The results of the analysis show that one of the factors causing gaps is partial monitoring. Therefore, an integrated monitoring system was created to controlling the execution of the investment budget. This system is expected to facilitate management in deciding on the investment budget.
\end{abstract}

Keywords : : Budget, Gap Analysis, Investment, Monitoring System, Revenue

Correspondence to : pu3.rositawati@gmail.com

\section{ABSTRAK}

Penelitian ini memaparkan terkait pengelolaan anggaran investasi di PT. Pembangkitan Jawa Bali. Anggaran investasi yang dikelola selama ini belum mencapai target yang ditetapkan. Dalam perkembangannya, ditemukan bahwa terdapat perbedaan antara nilai pendapatan di kontrak dengan rencana kerja anggaran unit dan realisasinya. Metode root cause problem solving dipilih untuk mengetahui akar masalah dan solusi terkait ini. Hasil analisis menunjukkan bahwa salah satu faktor penyebab munculnya gap adalah monitoring yang masih bersifat parsial. Oleh karena itu, dibuatlah sebuah sistem monitoring yang terintegrasi untuk mengawal eksekusi anggaran investasi. Sistem ini diharapkan dapat memudahkan pengambilan keputusan manajemen atas progress anggaran investasi.

Kata Kunci : : Anggaran, Investasi, Gap analisis, Pendapatan, Sistem monitoring

\section{Riwayat Artikel:}

Received : 03 Juni 2021

Revised : 28 Juni 2021

Accepted : 17 Juni 2021

\section{PENDAHULUAN}

Salah satu kunci kesuksesan perusahaan adalah penyusunan dan pengelolaan anggaran perusahaan yang efektif dan efisien. Hal ini akan mendukung kinerja perusahaan dalam mencapai tujuan utama perusahaan. Menurut Muhaimin, dkk (2012:223), penyusunan anggaran didasarkan pada rencana kegiatan atau program yang telah disusun dan 
kemudian diperhitungkan berapa biaya yang diperlukan untuk melaksanakan kegiatan tersebut, bukan dari jumlah dana yang tersedia dan bagaimana dana tersebut dihabiskan. Sedangkan pengelolaan anggaran dilaksanakan berdasarkan anggaran perusahaan yang telah ditetapkan dan disetujui oleh manajemen perusahaan. Anggaran dapat diartikan juga sebagai istilah perencanaan untuk pengendalian laba secara menyeluruh dan dapat didefinisikan secara luas sebagai suatu anggaran sistematis dan formal untuk perencanaan, pengkoordinasian dan pengendalian tanggung jawab manajemen (Welsch, 2000). Sedangkan laporan keuangan adalah hasil dari proses akuntansi dan merupakan informasi historis. Akuntansi adalah proses pengidentifikasian, mengukur dan melaporkan informasi ekonomi untuk membuat pertimbangan dan mengambil keputusan yang tepat bagi pemakai informasi tersebut (Sadeli, 2002).

Sebagai salah satu perusahaan yang bergerak di bidang pembangkit listrik, PT Pembangkitan Jawa Bali mempunyai bisnis jasa operasi dan pemeliharaan pembangkit listrik. Unit bisnis jasa operasi dan pemeliharaan ini terletak di wilayah Sumatra. (Pembangkitan Jawa Bali, 2019) Kontrak pengelolaan unit bisnis jasa operasi dan pemeliharaan berjalan mulai tahun 2018 . Namun selama periode kontrak berjalan, anggaran investasi pada unit bisnis jasa operasi dan pemeliharaan tidak pernah mencapai target yang ditetapkan. Hal ini ditunjukkan dengan adanya perbedaan (gap) antara nilai pendapatan di kontrak jasa operasi dan pemeliharaan dengan rencana kerja anggaran unit dan nilai realisasi tagihan atas program investasi unit bisnis jasa operasi dan pemeliharaan di Sumatra. Gap ini menyebabkan berkurangnya profit atas investasi di akhir periode kontrak jasa operasi dan pemeliharaan pembangkit listrik.

TABEL 1. Mengelola Kontrak/ Perjanjian dengan Pelanggan Bisnis Jasa O\&M

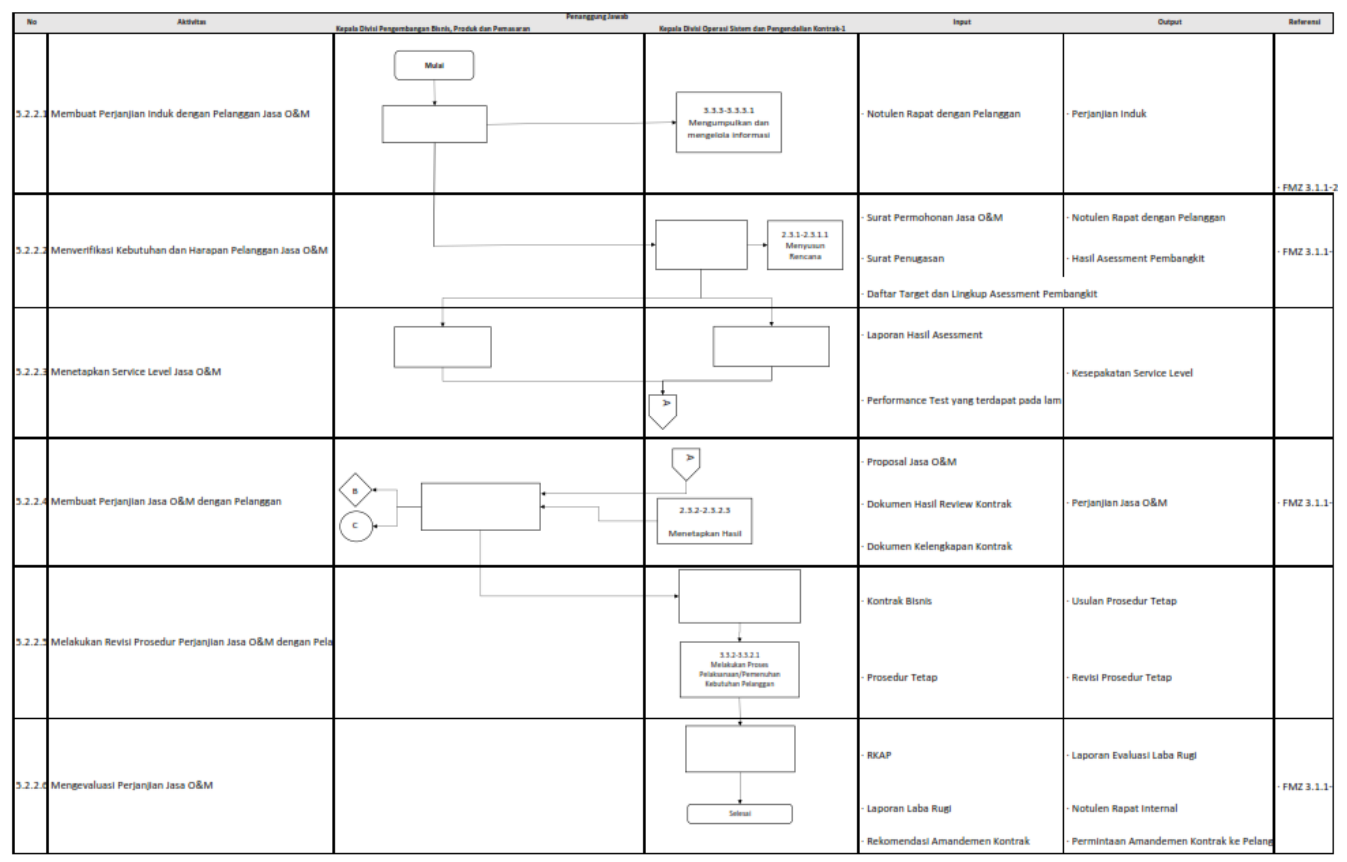

Sumber: Dokumen Kontrak Bisnis Jasa Operasi dan Pemeliharaan PT Pembangkitan Jawa Bali 
Penjelasan masing-masing aktivitas dalam flowchart di atas adalah sebagai berikut:

1. Membuat Perjanjian Induk dengan Pelanggan Jasa O\&M (5.2.2.1)

Manajer Pengembangan Produk pada Divisi Pengembangan Bisnis, Produk dan Pemasaran menyusun Perjanjian Induk sebagai Memorandum of Understanding (MoU) untuk pelaksanaan jasa O\&M oleh perusahaan selaku penyedia jasa O\&M kepada pelanggan selaku penerima jasa. Isi dari perjanjian didasari oleh Notulen Rapat hasil diskusi dengan pelanggan.

2. Memverifikasi Kebutuhan dan Harapan Pelanggan Jasa O\&M (5.2.2.2)

Manajer Pengendalian Kontrak Jasa O\&M dan AMC-1 Divisi Operasi Sistem dan Pengendalian Kontrak-1 berdiskusi dengan pelanggan terkait proyek jasa O\&M melalui rapat, surat atau media lainnya. Dalam mengidentifikasi kebutuhan dan harapan pelanggan, diskusi dapat dilakukan berulang kali dimulai dari pembahasan awal hingga verifikasi.Hal ini bertujuan agar kebutuhan dan harapan dapat tersampaikan secara spesifik dan benar. Dokumen yang digunakan perusahaan sebagai awal aktivitas ini adalah Surat Permohonan Jasa O\&M dan Surat Penugasan dari pelanggan. Dokumen yang dihasilkan adalah Notulen Rapat dengan pelanggan dan Daftar Target dan Lingkup Assessment yang akan digunakan Tim Assessor dalam mengkaji pembangkit.

\section{Menetapkan Service Level Jasa O\&M (5.2.2.3)}

Kepala Divisi Pengembangan Bisnis, Produk dan Pemasaran bersama dengan Kepala Divisi Operasi Sistem dan Pengendalian Kontrak-1 juga pelanggan menetapkan dan menyepakati tingkat layanan/service level yang akan diberikan perusahaan ke pelanggan. Service level ini merupakan target yang seharusnya dipenuhi perusahaan untuk dapat selaras atau memuaskan harapan pelanggan. Dokumen Teknis Pembangkitdigunakan sebagai dasar formulasi dan penyusunan service level.

\section{Membuat Perjanjian Jasa O\&M dengan} Pelanggan (5.2.2.4)

Manajer Pengembangan Produkpada Divisi Pengembangan Bisnis, Produk dan Pemasaran menyusun Perjanjian Jasa O\&M sebagai hasil kesepakatan para pihak yang mengatur tentang teknis pekerjaan.Perjanjian ini merupakan referensi perusahaan dalam melaksanakan pekerjaan O\&M-nya. Isi dari perjanjian didasari oleh Proposal Jasa O\&M yang merupakan hasil dari pelaksanaan assessment pembangkit. Dokumen lain yang digunakan dalam pembuatan perjanjian adalah Dokumen Hasil Review Perjanjian dari pihak legal dan Dokumen Pengadaan.

5. Melakukan Revisi Prosedur Tetap Perjanjian Jasa O\&M dengan Pelanggan (5.2.2.5)

Kepala Divisi Operasi Sistem dan Pengendalian Kontrak-1 bersama dengan pelanggan berdiskusi terkait prosedur tetap pelaksanaan kontrak bisnis.Prosedur ini mengatur komunikasi, transaksi, serta operasi dan pemeliharaan pembangkit.Hal ini tertuang dalam dokumen Pedoman Operasi Baku Pengelolaan Tenaga Listrik, Aturan Transaksi Tenaga Listrik dan Deklarasi Kondisi Pembangkit-Indeks Kinerja Pembangkit. Prosedur tetap dapat berbeda antar kontrak bisnis, tergantung kesepakatannnya dengan pelanggan. Jika perubahan prosedur diperlukan, perusahaan dapat memberikan Usulan dan/atau Revisi prosedur tetap ke pelanggan.

6. Mengevaluasi Perjanjian Jasa O\&M (5.2.2.6)

Manajer Pengendalian Kontrak Jasa O\&M dan AMC-1 bersama-sama dengan 
Manajer Pengendalian Anggaran Jasa O\&M dan AMC-1 pada Divisi Operasi Sistem dan Pengendalian Kontrak-1 mengevaluasi kinerja pekerjaan dengan melakukan kajian dari sudut pandang komersial atau profitabilitas bisnis. Evaluasi perjanjian menggunakan dokumen RKAP, Laporan Laba Rugi dan Rekomendasi Amandemen Kontrak (jika memang diberikan pihak operasi). Hasil evaluasi meliputi Laporan Evaluasi Laba Rugi, Notulen Rapat Internal dan Permintaan Amandemen Kontrak ke pelanggan (jika diperlukan).

TABEL 2. RACI Chart Mengelola Kontrak/ Perjanjian dengan Pelanggan Bisnis Jual Beli Jasa O\&M (Operasi dan Pemeliharaan)

\begin{tabular}{|c|c|c|c|}
\hline \multirow[t]{3}{*}{ No } & \multirow[t]{3}{*}{ Aktivitas } & \multicolumn{2}{|c|}{ Dir Ops-1 } \\
\hline & & \multicolumn{2}{|c|}{ Divisi OSK-1 } \\
\hline & & $\begin{array}{c}\text { Kadiv } \\
\text { BPM }\end{array}$ & $\begin{array}{c}\text { Kadiv } \\
\text { OSK - } 1\end{array}$ \\
\hline 1 & $\begin{array}{lr}\text { Membuat Perjanjian } \\
\text { Induk } & \text { dengan } \\
\text { Pelanggan } & \text { Jasa } \\
\text { O\&M } & \end{array}$ & $\mathrm{R}$ & \\
\hline 2 & $\begin{array}{l}\text { Memverifikasi } \\
\text { Kebutuhan dan } \\
\text { Harapan Pelanggan } \\
\text { Jasa O\&M }\end{array}$ & & $\mathrm{R}$ \\
\hline 3 & $\begin{array}{l}\text { Menetapkan } \\
\text { Service Level Jasa } \\
\text { O\&M }\end{array}$ & I & I \\
\hline 4 & $\begin{array}{l}\text { Membuat Perjanjian } \\
\text { Jasa O\&M dengan } \\
\text { Pelanggan }\end{array}$ & $\mathrm{R}$ & \\
\hline 5 & $\begin{array}{lr}\text { Melakukan } & \text { Revisi } \\
\text { Prosedur } & \text { Tetap } \\
\text { Perjanjian } & \text { Jasa } \\
\text { O\&M } & \text { dengan } \\
\text { Pelanggan } & \end{array}$ & & $\mathrm{R}$ \\
\hline 6 & $\begin{array}{l}\text { Mengevaluasi } \\
\text { Perjanjian Jasa } \\
\text { O\&M }\end{array}$ & I & $\mathrm{R}$ \\
\hline
\end{tabular}

Sumber : Kontrak Bisnis Jasa Operasi dan Pemeliharaan
Keterangan :

$\mathrm{R}=$ Responsible - Pihak yang melaksanakan aktivitas

$\mathrm{A}=$ Accountable - Pihak yang bertanggungjawab memberikan keputusan final

$\mathrm{C}=$ Consulted - Pihak yang harus dimintakan umpan balik dan sarannya sebelum diambil keputusan

I = Informed - Pihak yang harus diberi informasi setelah aktivitas selesai dilakukan

Berdasarkan uraian diatas, metode root cause problem solving dipilih untuk digunakan dalam penelitian ini untuk mengetahui akar masalah dan solusi atas gap pendapatan investasi. Menurut Mega AD Retnani, analisis penyebab merupakan suatu proses dalam mencari akar penyebab masalah kesenjangan atau gap kinerja dalam suatu organisasi. Langkah ini akan memberikan gambaran tentang akar penyebab dari suatu masalah secara detail dan mengidentifikasi unit organisasi mana yang memerlukan penanganan, serta memberikan solusi atau intervensi untuk memperbaiki serta mencari tahu cara organisasi agar dapat menerapkan perubahan demi meningkatkan kualitas kinerja yang dalam hal ini merupakan kinerja pembangkit listrik unit bisnis jasa operasi dan pemeliharaan di Sumatra. (Pratiwi, 2010)

\section{METODE PENELITIAN}

Penelitian ini menggunakan metode penelitian root cause problem solving untuk mengetahui akar masalah dan solusi atas gap pendapatan bisnis jasa operasi dan pemeliharaan. Metode ini dapat digunakan untuk mencari penyebab-penyebab dari suatu permasalahan. Metode analisis yang digunakan adalah gap analysis yang bertujuan untuk mengetahui tingkat kinerja suatu perusahaan, lembaga atau institusi. Dengan kata lain gap analysis merupakan suatu metode yang digunakan untuk mengetahui kinerja dari suatu sistem yang sedang berjalan dibandingkan dengan sistem standar. Tingkat kinerja ini dapat diketahui dengan membandingkan antara hasil yang dicapai selama pelaksanaan dengan hasil yang diharapkan dalam perencanaan.

\section{HASIL PENELITIAN}

Hasil analisa dengan menggunakan pendekatan gap analysis terhadap pendapatan investasi unit bisnis jasa operasi dan 
pemeliharaan di Wilayah Sumatera ditunjukkan pada tabel berikut:

TABEL 3. Gap Analysis Pendapatan Investasi Unit Bisnis Jasa Operasi dan Pemeliharaan Sumatera Tahun 2018

\begin{tabular}{lcccc}
\hline No & $\begin{array}{c}\text { A } \\
\text { (Juta Rp) }\end{array}$ & $\begin{array}{c}\text { B } \\
\text { (Juta Rp) }\end{array}$ & $\begin{array}{c}\text { C } \\
(\%)\end{array}$ & D \\
\hline 1 & 99 & 74 & 24.42 & 44 \\
\hline 2 & 4 & 3 & 17.29 & 162 \\
\hline 3 & 53 & 53 & 0.40 & 100 \\
\hline 4 & 30 & 29,9 & 2.62 & 117 \\
\hline
\end{tabular}

Sumber : Kontrak Bisnis Jasa Operasi dan Pemeliharaan PT. Pembangkitan Jawa Bali

Keterangan :

1.Unit PLTMG Arun

2.Unit PLTU Tenayan

3.Unit PLTU Air Anyir Bangka

4.Unit PLTU Air Anyir Suge Belitung

A.Nilai Kontrak
B Nilai Realisasi
C Gap
D Jumlah Program Investasi

Berdasarkan tabel gap analysis di atas, diperlukan monitoring dan pengendalian anggaran terhadap eksekusi atas pekerjaan investasi untuk mengawal pendapatan investasi unit bisnis jasa operasi dan pemeliharaan di Sumatra untuk mengurangi potensi berkurangnya profit atas pendapatan investasi terhadap eksekusi pekerjaan investasi tahun berikutnya. Proses monitoring dan pengendalian anggaran atas eksekusi program investasi jasa operasi dan pemeliharaan saat ini dilakukan melalui tiga tahapan utama yaitu perencanaan, pelaksanaan dan penagihan program investasi. (Badan Perencanaan Pembangunan Nasional, 2009) Berdasarkan identifikasi program investasi maka dibuatlah bagan alur baru secara mendetail terhadap keseluruhan proses monitoring dan pengendalian eksekusi program investasi dengan menggunakan bagan proses berikut :

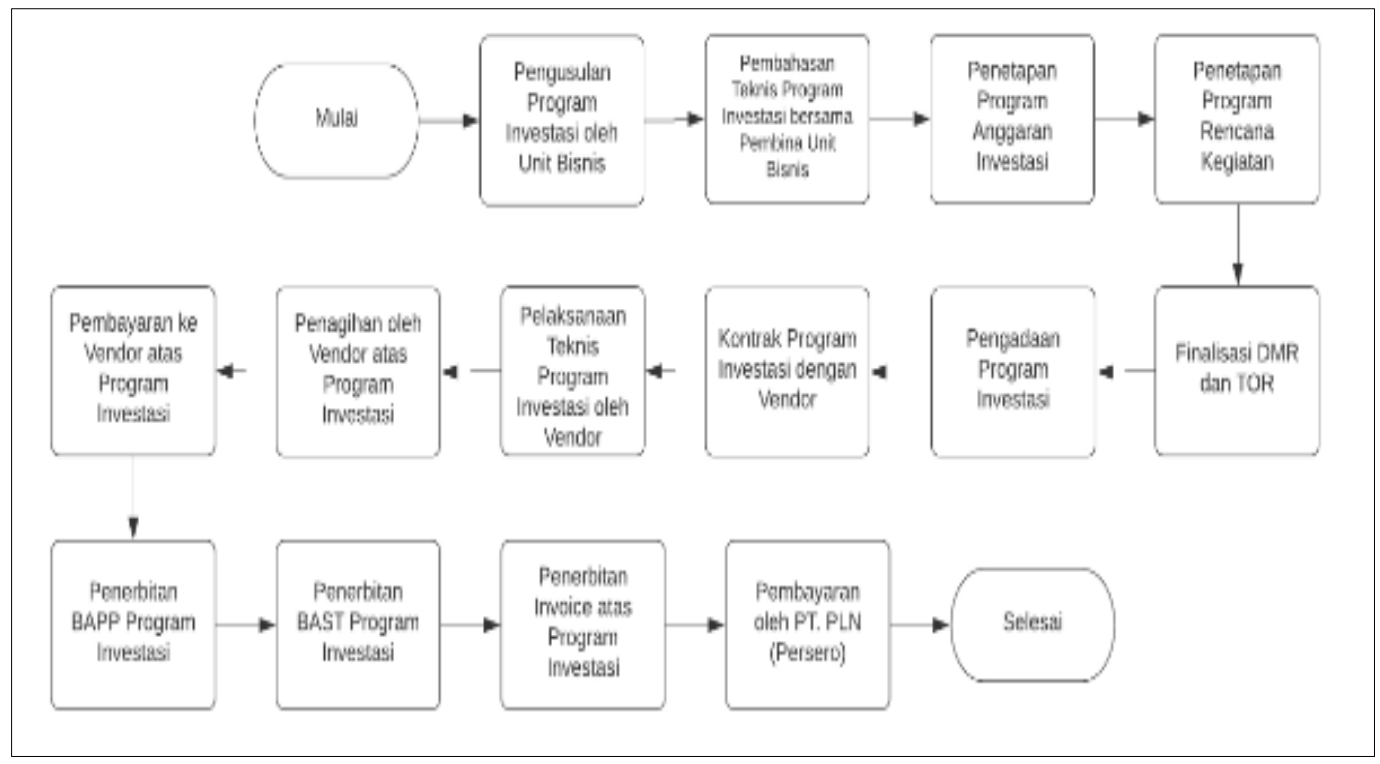

Sumber: Data diolah dari Hasil Wawancara dan Brainstorming

Gambar 1.

Bagan Alur Proses Monitoring dan Pengendalian Anggaran Program Investasi Unit Bisnis Jasa Operasi dan Pemeliharaan Wilayah Sumatra 
Berdasarkan bagan proses diatas, PT. Pembangkitan Jawa Bali pada saat ini hanya berfokus pada tahap penagihan. Sedangkan pada tahapan perencanaan dan pelaksanaan program investasi belum dimonitoring secara optimal atas program investasi yang telah berjalan. Berdasarkan permasalahan di atas, dilakukan identifikasi proses monitoring dan pengendalian anggaran atas eksekusi program investasi untuk tahap perencanaan dan pelaksanaan program investasi. Identifikasi ini dilakukan dengan mengumpulkan data dan informasi lewat prosedur, peraturan dan pedoman perusahaan yang ada. Berdasarkan hasil identifikasi yang telah dilakukan, permasalahan terkait unit bisnis jasa operasi dan pemeliharaan wilayah Sumatra yang diambil dari gap analysis dipetakan dengan menggunakan Root Cause Problem Solving untuk mengetahui akar masalah dan solusi. (Mahachandra et al., 2019) Berikut ini merupakan Root Cause Problem Solving atas program investasi unit bisnis jasa operasi dan pemeliharaan wilayah Sumatra :

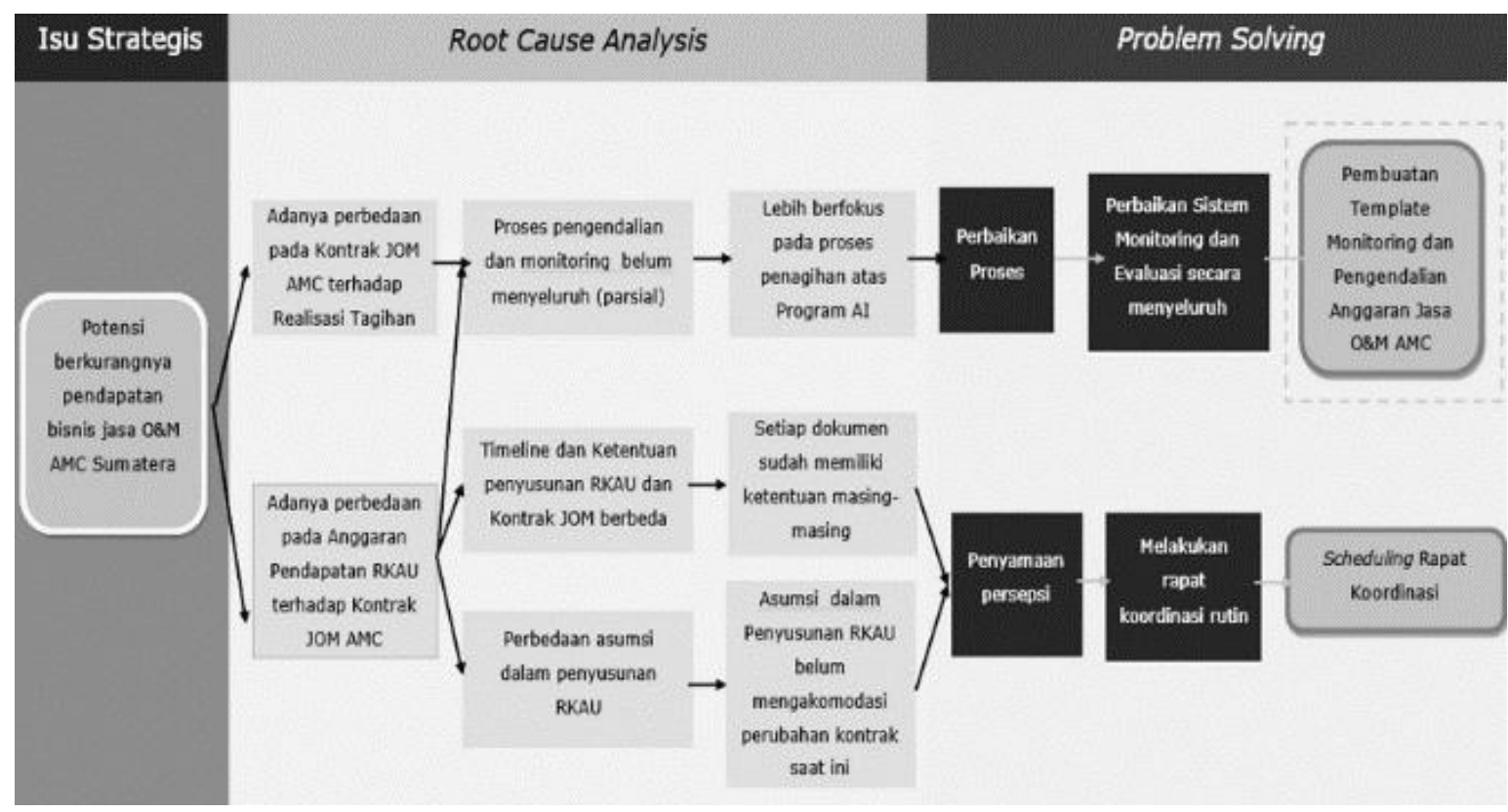

Sumber: Data diolah dari Hasil Wawancara dan Brainstorming

Gambar. 2

Root Cause Problem Solving

Pada gambar di atas memetakan permasalahan, yakni hubungan antara potensi berkurangnya pendapatan unit bisnis jasa operasi dan pemeliharaan terhadap gap yang tampak, yaitu perbedaan antara nilai kontrak jasa operasi dan pemeliharaan dibandingkan dengan rencana kerja anggaran unit tahun 2018 serta realisasi anggaran investasi yang terjadi di Unit. Semua perbedaan tersebut kemudian dipetakan terhadap akar-akar penyebab yang bermuara pada salah satu akar penyebab yaitu proses monitoring dan pengendalian anggaran investasi masih bersifat parsial dimana fungsi pengendalian anggaran investasi hanya berfokus pada proses penagihan. Sehingga solusi yang diusulkan untuk meminimalkan potensi berkurangnya pendapatan investasi jasa operasi dan pemeliharaan adalah pembuatan template monitoring pengendalian anggaran investasi jasa operasi dan pemeliharaan untuk mengawal pelaksanaan eksekusi pekerjaan 
investasi pada unit bisnis jasa operasi dan pemeliharaan wilayah Sumatra. (Sony Y, 2005)

Template monitoring pengendalian anggaran investasi jasa operasi dan pemeliharaan unit bisnis wilayah Sumatra digunakan untuk memperbaiki sistem monitoring pengendalian anggaran investasi yang pada saat ini yang belum bersifat menyeluruh di PT. Pembangkitan Jawa Bali. Template monitoring pengendalian anggaran investasi yang diusulkan akan menjadi alat bantu dalam melakukan koordinasi dengan unit bisnis jasa operasi dan pemeliharaan, divisi, maupun pembina terkait dalam progress pelaksanaan eksekusi pekerjaan investasi dalam mengawal pendapatan investasi agar mencapai target sesuai kontrak yang telah disepakati. Template monitoring anggaran investasi ini bersifat secara menyeluruh, sehingga diharapkan dapat menjadi early warning system dalam meminimalisasi potensi berkurangnya pendapatan investasi tahun berikutnya. (Yudha et al., 2017)

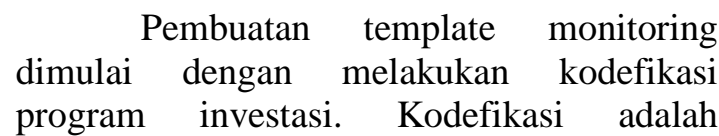
pemberian kode nomor unik untuk setiap pekerjaan investasi. Tujuannya adalah untuk memastikan history pekerjaan investasi dalam setiap tahapan serta untuk menghindari adanya duplikasi program investasi yang sama di tahun berikutnya. Tahap berikutnya adalah mengkategorikan tahapan monitoring proses pelaksanaan eksekusi program pekerjaan investasi. Proses ini dilakukan dengan memetakan proses monitoring dan pengendalian anggaran secara menyeluruh. Berdasarkan proses bisnis yang telah berjalan, dilakukan penomoran tahapan (pemberian status) yang pada alur yang telah berjalan. Hal ini digunakan untuk memudahkan dalam tracking alur proses bisnis yang sedang berjalan. Kodefikasi dilakukan dengan aturan format sebagai berikut :

\section{TY-YY- OX - 000-P0X}

Keterangan :

- TY : Menyatakan Unit Jasa Operasi dan Pemeliharaan

- YY : Tahun terkontrak program

- 0X : Sasaran Program 01, 02, 03.. dst

- 000 P0X: Menyatakan Penomoran program investasi ke- 1,2 , X, dst

- 001-dst P0X : Menyatakan Penomoran Sub program atas program investasi ke- $X$

Selanjutnya adalah membuat template monitoring proses pelaksanaan eksekusi program pekerjaan investasi. Template monitoring dibuat menggunakan spreadsheet Microsoft Excel dengan memanfaatkan secara optimal fungsi dan formulasi yang telah ada dengan tujuan menyajikan informasi yang diinginkan. Informasi yang diinginkan adalah terkait pemantauan progress pelaksaan eksekusi pekerjaan investasi yang sudah terlaksana dan nilainya serta prediksi akan nilai tagihan pendapatan investasi yang akan diperoleh. Prediksi atas nilai final pendapatan investasi kontrak bisnis jasa operasi dan pemeliharaan bersifat penting karena digunakan sebagai bahan evaluasi dan tindak lanjut top management. Berikut ini merupakan template yang digunakan untuk melakukan monitoring atas eksekusi program investasi kontrak bisnis jasa operasi dan pemeliharaan wilayah Sumatra :

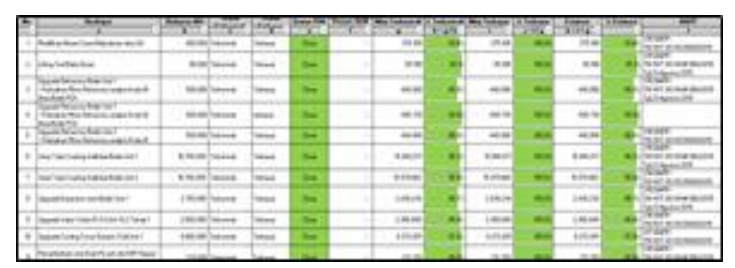

Gambar. 3

Template Monitoring dan Pengendalian Eksekusi Program Investasi Unit Bisnis Jasa Operasi dan Pemeliharaan Wilayah Sumatra. 
PEMBAHASAN

Berdasarkan hasil penelitian diatas menunjukkan bahwa sistem monitoring dan pengendalian anggaran investasi yang baru memberikan kemudahan bagi user untuk melakukan pekerjaannya. System yang sebelumnya parsial menjadi menyeluruh dalam bentuk template monitoring sehingga dapat mempermudah dalam mengawal program investasi unit bisnis jasa operasi dan pemeliharaan di PT. Pembangkitan Jawa Bali. Hal ini dapat dilihat dari mapping proses bisnis dimana yang sebelumnya hanya berfokus pada penagihan, sekarang juga berfokus pada tahap planning dan pelaksanaan program investasi pembangkit listrik.

Template monitoring ini juga dapat digunakan sebagai dasar referensi informasi bagi top management untuk mengambil keputusan terkait pelaksanaan eksekusi program investasi pada unit bisnis jasa operasi dan pemeliharaan sedini mungkin yang dapat berpengaruh pada hasil akhir capaian nilai pendapatan investasi.

Dengan adanya monitoring dan pengendalian anggaran investasi ini diharapkan tidak ada lagi program investasi yang mengalami pengulangan atau duplikasi di tahun berikutnya dengan cara melalui kodefikasi program investasi yang memudahkan pelacakan program investasi setiap unit bisnis jasa operasi dan pemeliharaan.

\section{KESIMPULAN}

Sistem monitoring pengendalian anggaran investasi PT. Pembangkitan Jawa Bali saat ini masih bersifat parsial. Hal ini mengakibatkan kegiatan pengendalian dan pengawalan eksekusi pekerjaan investasi pada unit bisnis jasa operasi dan pemeliharaan belum mencapai titik optimal yang berpengaruh pada realisasi pendapatan investasi di tahun selanjutnya.

Perbaikan monitoring dan evaluasi pengendalian anggaran bisnis jasa operasi dan pemeliharaan dengan usulan pembuatan template ini diharapkan dapat mengawal eksekusi pekerjaan investasi secara menyeluruh dan meminimalkan potensi berkurangnya pendapatan investasi dari yang ditargetkan sesuai kontrak bisnis jasa operasi dan pemeliharaan untuk tahun-tahun mendatang.(Adafin, 2019)

Penelitian ini masih mempunyai banyak keterbatasan, oleh karena itu kami berharap terdapat penelitian-penelitian lain yang mendukung untuk memperkaya penelitian terkait bidang pengelolaan anggaran investasi pada bidang jasa operasi dan pemeliharaan pembangkit listrik.

\section{DAFTAR PUSTAKA}

Badan Perencanaan Pembangunan Nasional. (2009). Pedoman Evaluasi Kinerja Pembangunan Sektoral. BPPN, 35.

Mahachandra, M., Situmorang, W., \& Handayani, N. U. (2019). Implementasi 5S dengan Teknik Root Cause Problem Solving pada Gudang Logistik PT. PLN (Persero) Area Lubuk Pakam. Seminar Nasional IENACO, 222-227.

Pembangkitan Jawa Bali, P. (2019). Perjanjian Induk antara PT PLN (Persero) dengan PT Pembangkitan Jawa Bali tentang Pengelolaan Aset Pembangkit PLTU di Wilayah Sumatra. In PT PLN (Persero) (Vol. 53, Issue 9).

Pratiwi, O. E. (2010). Teknik Penjadwalan Proses Produksi Batik Motif Kembang Api Dengan Metode Pert Dan Cpm Pada Pt. Batik Semar Surakarta. UNS.

Sony Y, D. (2005). Penganggaran Sektor Publik. Bayumedia Publishing.

Yudha, B. S., Haryono, I., \& Suwarsono, L. W. (2017). Perancangan Job Description Kerangka Business Process Pada CV. Gradient. EProceeding of Engineering, 4(2), 2529-2534. 
BALANCE : Economic, Business, Management, and Accounting Journal Vol. XVIII No. 2 |Bulan Juli Tahun 2021

P-ISSN 1693-9352 | E-ISSN 2614-820x

Adafin, J. (2019). An Assessment of Risk Factors Impacting Budget Variability in New Zealand Commercial Construction Projects. Research Gate, Res.

Gate. https://www.researchgate.net/publica tion/337877479_An_Assessment_of_ Risk_Factors_Impacting_Budget_Va
riability_in_New_Zealand_Commerc ial_Construction_Projects 